NASA

Technical Memorandum 87174
USAAVSCOM

Technical Report 85-C-20

\title{
Starvation Effects on the Hydrodynamic Lubrication of Rigid Nonconformal Contacts in Combined Rolling and Normal Motion
}

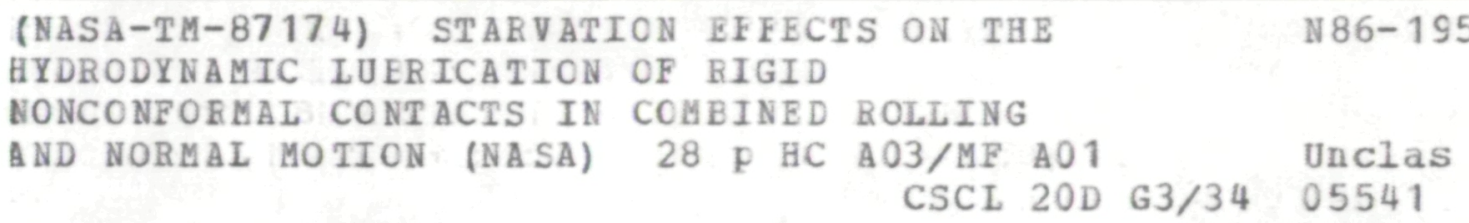

M.K. Ghosh

Lewis Research Center

Cleveland, Ohio

B.J. Hamrock

Ohio State University

Columbus, Ohio

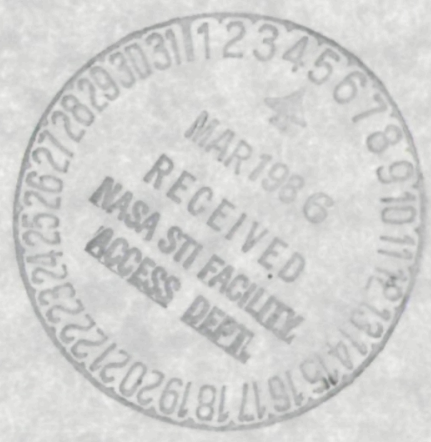

D.E. Brewe

Propulsion Directorate

U.S. Army Aviation Research and Technology Activity-AVSCOM

Lewis Research Center

Cleveland, Ohio

Prepared for the

1986 Annual Meeting of the American Society of Lubrication Engineers

Toronto, Canada, May 12-15, 1986 
STARVATION EFFECTS ON THE HYDRODYNAMIC LUBRICATION OF RIGID NONCONFORMAL

CONTACTS IN COMBINED ROLLING AND NORMAL MOTION

M. K. Ghosh*

National Aeronautics and Space Administration

Lewis Research Center

Cleveland, Ohio 44135

and

B. J. Hamrock

Ohio State University

Columbus, Ohio

and

D. E. Brewe

Propulsion Directorate

U.S. Army Aviation Research and Technology Activity - AVSCOM

Lewis Research Center

Cleveland, Ohio 44135

\section{Abstract}

The effect of inlet starvation on the hydrodynamic iubrication of lightiy loaded rigid nonconformal contacts in combined rolling and normal motion is determined through a numerical solution of the Reynolds' equation for an

$\approx$ isoviscous, incompressible lubricant. Starvation is effected by systematically reducing the fluid inlet level. The pressures are taken to be ambient at the inlet meniscus boundary and Reynolds' boundary condition is applied for film rupture in the exit region. Results are presented for the dynamic performance of the starved contacts in combined rolling and normal motion for both normal approach and separation.

It has been found that during normal approach the dynamic load ratio (1.e. ratio of dynamic to steady state load capacity) increases considerably with increase in the inlet starvation. The reverse effect is observed during

*Banaras Hindu University, Varanasi, India and NRC-NASA Research Associate. 
separation when the dynamic load ratio reduces significantiy. The effect of starvation on the dynamic peak pressure ratio is relatively small. Further, it has been observed that with increasing starvation, film thickness effects become significant in the dynamic behavior of the nonconformal contacts. For significantly starved contacts the dynamic load ratio increases with increase in film thickness during normal approach and a similar reduction is observed during separation. A similar effect is noted for the dynamic peak pressure ratio. Ninety five cases were run to incorporate the effects of starvation and film thickness on the dynamic load ratio and the peak pressure ratio as obtained in an earlier investigation for fully flooded contacts.

\section{NOMENCLATURE}

$h_{0} \quad$ central (or minimum) film thickness, $m$

h film thickness, m

H dimensionless film thickness, $h / R_{x}$

Ho dimensionless central (or minimum) film thickness, $h_{0} / R_{X}$

hin fluid inlet level, $m$

$H_{\text {in }}$ dimensionless fluid inlet level, $h_{i n} / R_{x}$

p pressure, $n / m^{2}$

$\mathrm{P}$ dimensionless pressure, $\mathrm{pR} R_{\mathrm{X}} / \mathrm{n}_{0} U_{S}$

Pmax maximum or peak pressure along the line of minimum film thickness $\mathrm{N} / \mathrm{m}^{2}$

$P_{\max }$ dimensionless peak pressure along the line of minimum film thickness, $P_{\max } R_{x} / n_{0} U_{s}$

$R$ effective radius of curvature, $\frac{R_{x} R_{y}}{R_{x}+R_{y}}, m$

$S$ separation due to geometry of solid, $m$

$U_{A}, U_{B}$ surface velocity of solids $A$ and $B$

$U_{S} \quad$ Average surface velocity $\left(U_{A}+U_{B}\right) / 2, m$ 


$$
\begin{aligned}
& U_{N} \text { normal velocity of approach or separation of solids, } m \\
& \bar{U}_{N} \text { dimensionless normal velocity, } U_{N} / U_{S} \\
& \text { t time, sec } \\
& \text { q dimensioniess normal velocity parameters } \frac{U_{N}}{U_{S}}\left(\frac{1}{2 H_{0}}\right)^{1 / 2} \\
& x_{p} \text { dimensionless location of peak pressure from the minimum film } \\
& \text { thickness position on the line of minimum film thickness, } x_{p} / R_{x} \\
& X_{r} \text { dimensionless location of film rupture boundary from the minimum film } \\
& \text { thickness position on the line of minimum film thickness, } x_{r} / R_{x} \\
& x \quad \text { coordinate along rolling direction, } m \\
& \text { y coordinate transverse to rolling direction, m } \\
& x \text { dimensionless coordinate, } x / R_{x} \\
& Y \text { dimensionless coordinate, } y / R_{x} \\
& x_{p} \quad \text { location of peak pressure from the minimum film thickness position, } m \\
& x_{r} \quad \text { location of film rupture boundary from the minimum film thickness } \\
& \text { position, } m \\
& \text { W load carrying capacity, } N \\
& \text { W dimensionless load carrying capacity, } W / n_{0} U_{S} R_{x} \\
& \text { a radius ratio (geometry parameter), } R_{y} / R_{x} \\
& \text { B dynamic load ratio ie., ratio of dimensioniess dynamic to steady state } \\
& \text { load carrying capacity, } W /(W)_{q}=0.0 \\
& \xi \text { dynamic peak pressure ratio ie., ratio of dimensionless dynamic to } \\
& \text { steady state peak pressure, } P_{\max } /\left(P_{\max }\right)_{q}=0.0 \\
& \text { no fluid viscosity at standard temperature and pressure, NS/m2 }
\end{aligned}
$$

\section{INTRODUCTION}

Starved lubrication of rolling element bearings has attracted the attention of tribologists for many years. There has been growing interest in recent years as it has been shown that most high speed bearings operate under starved condition. It has been observed that starvation can significantiy influence the film formation and can limit the film thickness generated 
severely in the nonconformal contacts. For example, the roller end and the flange are often subjected to depletion of lubricant supply due to centrifugal effects in high speed cylindrical roller bearings and therefore roller end wear due to roller skewing can be a critical problem there. Starvation is thus of very practical importance in the study of bearing failure and wear. Restricted lubricant supply to a roller bearing was seen to experimentally and theoretically reduce the amount of cage and roller slip (Boness, 1970). In an experimental investigation Horsch (1963) showed that the film thickness increases with increase in speed, reaches a maximum and then starts decreasing for further increase in speed. Chiu (1974) experimentally investigated starvation in rolling contact systems and also observed significant reduction in film thickness for high speeds of operation after reaching the maximum plateau. In his theoretical study he developed a fluid replenishment model for the system and predicted film thickness reduction with speed for higher speeds as a function of degree of replenishment. It was shown that surface tension plays a significant role in the mechanism of starvation. The mechanism of fluid replenishment was also invoked later by Pamberton and Cameron (1976).

However, the location of inlet meniscus boundary and the exit boundaries, as well as, the respective boundary conditions to be applied has been one of the most controversial issues concerning starvation of hydrodynamic contacts. The issue of the lubricant supply on the inlet boundary condition and its consequences on the incipient pressure bulid up attracted the most attention. Lauder (1966) used the reverse flow boundary conditions (i.e. $u=\partial u / \partial y=0$ ) to locate the position of the incipient pressure build up in the inlet while Tipei (1968) asserted an upstream limit to the fluid film where the pressure begins to rise as governed by the Reynolds' equation and defined this limit by the line of centers of two bounded vortices in pure rolling. However, both 
cases lead to only one position of the pressure build up regardless of the ofl supply (Saman 1974). Dowson (1968) and Floberg $(1965,73)$ supported the idea that the location of incipient pressure rise depended on the lubricant supply. Experimental investigation by Dowson (1968) and most dramatically by Wedeven et a 1. (1971) provided the evidence most needed to support this idea. Good correlation between experiment and theory was obtained by Wedeven et al. using a Grubin type EHD analysis by choosing the start of the pressure build up at the meniscus boundary. Oteri (1972) using stream function analysis for lubrication of rigid cylinders showed that incipient pressure rise occurs at the meniscus boundary even in the presence of reverse flow. The influence of starvation on the lubrication of rigid cylinders were studied by floberg $(1959,61)$. Dalmaz and Godet (1973) analyzed the effect of inlet starvation on the film thickness reduction in the case of lubrication of a sphere against a plate. Theoretical investigation on the influence of starvation on the elastohydrodynamic film thickness of line contacts were carried out by Wolveridge et al. (1971) and Castie and Dowson (1972) and for point contacts by Hamrock and Dowson $(1977,79)$. Brewe and Hamrock (1982) studied theoretically the effect of starvation in hydrodynamically lubricated conjunctions by systematically reducing the fluid inlet level and observing resultant pressure buildup for a given film thickness using Reynolds' boundary condition for film rupture in the exit region. Start of the pressure buildup was chosen to occur at the inlet meniscus boundary. A wide range of geometry parameters from a ball on a plate to a ball in a conforming groove were studied and the film thickness formula for a fully flooded conjunction was modified to incorporate the starvation effect into it. Recently Bonneau and Frene (1983) carried out a theoretical analysis of the film formation in the inlet of a starved contact in pure sliding taking recourse to the solution of Navier-Stokes equation for two dimensional flow in the inlet region with 
reverse flow and circulation. The effect of surface tension and feeding thickness on the meniscus shape and pressure build up was investigated in correlation with hydrodynamic effects. For large values of the parameter $\eta_{0} U / T$, (where $T$ is the surface tension of the fluid, and $U$ is the sliding velocity) film rupture in the inlet was observed that might lead to the fallure of the lubrication in the contact.

Lubrication of lightly loaded rigid cylinders in combined rolling and normal motion were investigated by several researchers (viz Sasaki et al. (1962), Dowson et al. (1976). The problem of the normal approach of cylinders in. an EHL regime were also addressed by several investigations e.g. Christensen (1961), Vichard (1971), Herrebrugh (1970), Lee and Cheng (1973) and recently by Chandra and Rogers (1983).

Hydrodynamic lubrication of nonconformal contacts in combined rolling and normal motion was investigated by Ghosh et al. (1983) where the influence of normal approach and separation was determined for a ball on a plate configuration to various other geometrical configurations covering the complete range. Fully flooded conditions were assumed for a dimensionless fluid inlet level of 0.035 . It was observed that normal motion resulted in considerably increased load capacity during normal approach and the pressure distributions in the contact were altered significantly by the normal motion. Reverse effects were observed during separation.

The present report is a sequel to the earlier investigation where it was observed that inlet starvation or fluid inlet level would have significant influence on the dynamic performance of nonconformal contacts in combined rolling and normal motion.

This report investigates the starvation effects on the hydrodynamic lubrication of nonconformal contacts in combined rolling and normal motion by systematically reducing the fluid inlet level from the assumed fully flooded 
level of 0.035 for both normal approach and separation. It has been found that starvation influences significantly the dynamic behavior of the conjunction. With increasing starvation, film thickness also affects the dynamic behavior of the conjunction appreciably. Ninety five cases were run to incorporate the effects of inlet starvation and film thickness on the dynamic load ratio and peak pressure ratio as obtained in an earlier investigation for fully flooded contacts.

\section{THEORY}

Theoretical analysis adopted here is similar to the analysis reported by the authors in the reference (1983). Hydrodynamic lubrication of rigid nonconformal contacts in combined rolling and normal motion is analyzed for various starvation levels in the inlet of the contact. The effects of starvation are determined by systematically reducing the fluid inlet level. The lubricant is assumed to be an incompressible, isoviscous newtonian fluid. The analysis treats the two rigid bodies as having parallel axes of inertia. This enables one to make a simplifying transformation to an equivalent system of a rigid solid near a plane separated by a lubricant film (Fig. 1).

The Reynolds' equation governing the flow of the lubricant in the conjunction is written as

$$
\frac{\partial}{\partial x}\left(h^{3} \frac{\partial p}{\partial x}\right)+\frac{\partial}{\partial y}\left(h^{3} \frac{\partial p}{\partial y}\right)=12 n_{0} U_{S} \frac{\partial h}{\partial x}+12 n_{0} U_{N}
$$

Using the same dimensionless expressions as reported earlier (1983), that is

$$
x=x / R_{x} ; \quad Y=y / R_{x}, \quad H=h / R_{X}, \quad P=p R_{x} / n_{0} U_{S}, \quad a=R_{y} / R_{X} ; \quad \bar{U}_{N}=U_{N} / U_{S}
$$

Eq. (1) reduces to

$$
\frac{\partial}{\partial X} H^{3} \frac{\partial P}{\partial X}+\frac{\partial}{\partial Y} H^{3} \frac{\partial P}{\partial Y}=12\left(\frac{\partial H}{\partial X}+\bar{U}_{N}\right)
$$

The above equation can be further expressed as

$$
\frac{\partial}{\partial X} H^{3} \frac{\partial P}{\partial X}+\frac{\partial}{\partial Y} H^{3} \frac{\partial P}{\partial Y}=12\left(\frac{\partial H}{\partial X}+\sqrt{2 H_{0}} q\right)
$$


where $\mathrm{q}=\bar{U}_{\mathrm{N}} /\left(2 \mathrm{H}_{0}\right)^{1 / 2}$, the dimensionless normal velocity parameter.

The dimensionless film thickness is given as below using the well known parabolic approximation

$$
H=H_{0}+\frac{x^{2}}{2}+\frac{y^{2}}{2 \alpha}
$$

where $H$ is bounded above by the dimensionless fluid inlet level $H_{\text {in }}$ and below by the dimensionless minimum or central film thickness $H_{0}$ (i.e. $H_{0} \leq H \leq H_{\text {in }}$ ) e.g., Fig. 2 .

A pressure distribution satisfying the Reynolds boundary conditions, 1.e., $P=\partial P / \partial N=0$ at the $f 11 \mathrm{~m}$ rupture or cavitation boundary and $P=0$ at the inlet boundary $\left(H=H_{i n}\right)$ is obtained by solving the Reynolds' equation for the lubrication in the contact given by Eq. (3) for a given geometry, speed, film thickness, viscosity and normal velocity parameter. The Reynolds' equation was written in the finite difference form using a central difference scheme and solved using a Gauss-Seidel iterative method with over-relaxation. Wherever needed a nonuniform grid structure was used. A fine mesh spacing of 0.001 and coarse mesh spacing of 0.01 was generally used. Otherwise only a fine mesh was used. For geometry parameters other than $\alpha=1.0$ boundaries were located according to the relationship $Y=\alpha^{0.5} X$ and a coarser grid in the $y$ direction was used for higher values of $\alpha$. The grid size was selected after a few trials. Pressure distributions for various conditions are shown in Fig. 3 that are self-explanatory. The inlet meniscus boundary is not shown.

The hydrodynamic load carrying capacity of the contact is obtained by integrating the pressure in the contact region and is given as:

$$
w=\int_{A} p d x d y
$$


In the dimensionless form it is expressed as:

$$
W=w / \eta_{0}^{\prime} \dot{U}_{S} R_{x}=\int_{A} \dot{P} d X d Y
$$

where $A$ is the domain of integration and is dependent on the fluid inlet level and the film rupture boundary.

The dynamic load ratio of the contact is expressed as (defined earlier in the authors reference, 1983):

$$
B=\frac{W}{(W)_{q=0.0}}
$$

where $(W)_{q=0.0}$ is the dimensioniess steady state load carrying capacity for the same minimum film thickness and given conditions as considered in determining $W$ for a given value of dimensioniess normal velocity parameter, q.

The parameters studied in the present numerical investigation are (1) the dimensionless normal velocity parameter, $q,(11)$ the inlet starvation parameter, $H_{i n}$ ( $i(i)$ the central film thickness, $H_{0}$, and (iv) the geometry parameter, $\alpha$.

RESULTS AND ÖISCUSSION

Results of the numerical calculations for the steady state and dynamic performance of the starved nonconformal contacts in normal approach and separation are presented for various inlet starvation parameters, geometry parameters and for various cential film thicknesses in the Tables 1 through 8.

In a preceding report by the authors (1983) it was pointed out that the normal vélocity parameter governs the dynamic performance of the rigid nonconformal contacts in combined roiling ànd normal motion under lightiy loaded conditions. The results revealed the functional dependence for the dynamic load ratio, and the peak pressure ratio with the normal velocity parameter for fully flooded conditions with à fluid inlet level of 0.035 . Some geometry dependence was also reported. Here, the results are presented 
in Tables 3 through 5 for varlous inlet starvation parameters for two dimensionless normal velocity parameters, $q=-1.0$ in normal approach and of $q=0.75$ in normal separation and for three different geometry parameters of $\alpha=0.2,1.0$ and 35.0 for a given dimensionless central film thickness $H_{0}$ of $1.0 \times 10^{-4}$. Results are plotted in the Figs. 4 and 5 that show the variation of dynamic load ratio, $B$, and the dynamic peak pressure ratio, $\xi$, with the inlet starvation parameter, $H_{\text {in }}$. It is observed that the dynamic load ratio, $B$ increases with increase in the severity of starvation in the inlet (i.e. for decrease in the inlet starvation parameter, $H_{\text {in }}$ ). The reverse effect is observed during normal separation. The influence of normal motion during approach is to alter the pressure distribution in the contact due to the squeeze action and raise the pressures in the contact. The squeeze action is predominant in a small area around the central film thickness and the effect is smaller comparatively in the far out inlet regions. Therefore, due to progressive dimunition of the inlet region for increasing starvation the overall effect on the dynamic load ratio is observed to be larger. However, with increase in starvation the steady state load capacity decreases by an even greater amount and therefore the over all dynamic load capacity of the contact decreases when compared to its dynamic load capacity in a fully flooded condition. The dynamic peak pressure ratio, 5 , is not altered appreciably by the increase in starvation. As may be seen in Fig. 5, the effect is noticeable for starvation parameters of 0.001 or less. However, for such low values of inlet starvation parameters the assumptions involved in the Reynolds' equation for the lubricant flow may be questioned, since the film thickness and the film length in the flow direction become of the same order. Therefore, in general it can be said that the peak pressures in the contact are not affected significantly by increase in starvation. It may be noted in the Table 1 that for steady state conditions also peak pressures do not change 
appreciably with increase in starvation. Further, it may be observed in the Tables 3 to 5 that the film rupture boundary and the location of the peak pressure on the line of central film thickness also do not change with increase in starvation for a given film thickness $H_{0}$ of $1.0 \times 10^{-4}$. During normal separation starvation effects are opposite to that of normal approach and result in reduced pressure in the contact. Therefore, with increasing starvation during normal separation the dynamic load ratio progressively decreases.

It was observed in the previous work by the authors (1983) that under fully flooded conditions varying the central film thickness had insignificant influence on the dynamic performance of the nonconformal contact, although the central film thickness implicitly enters as a parameter in the dimensionless normal velocity parameter ' $q$ ' and would therefore affect the dynamic load capacity of the contact for a given value of ' $q$ '. Results of numerical calculations for various central film thicknesses and starvation level, are presented in the Tables 6 to 8 and plotted in Figs. 6 and 7 for the dynamic load ratio and dynamic peak pressure ratio respectively. It may be noted that as the conjunction becomes starved, a significant increase in dynamic load ratio and peak pressure ratio are observed for increasing central film thickness during normal approach, whlle, similar reduction in the dynamic load ratio and peak pressure occur during normal separation. Therefore, in the starved contacts central film thickness affect the dynamic performance of the contact very significantly and the effect is pronounced at higher film thicknesses. Ninety five cases were run to incorporate starvation effects and the effect of central film thickness on the dynamic load ratio $B$, and the dynamic peak pressure ratio $\xi$. 


\section{CONCLUSIONS}

The following conclusions can be drawn from the numerical study of the problem of starved lubrication of nonconformal contacts in combined rolling and normal motion.

1. The dynamic load ratio during normal approach iricreases significantiy with increase in starvation of the contact while during separation a similar order of reduction of the dynamic load ratio, is observed. However, the dynamic load capacity of the contact reduces with increase in starvation when compared to its fully flooded dynamic load capacity.

2. The peak pressures generated in the contact are not affected apprectabily by the starvation of the contact.

3. In starved contacts, increase in central film thickness results in Increased dynamic load ratio "during normal approach and correspondingly reduced dynamic load ratio during separation. "Similar variatións are noted for the dynamic peak pressure ratio. This effect increases with increase in starvation of the contact.

4. Location of the peak pressure and the film rupture boundary on the line of minimum film thickness are not affected by the increase in inlet starvation.

\section{REFERENCES}

1. Boness, R.J.: The Effect of 011 'Supply on Cage and Roller Motion in a Lubricated Roller Bearing. J. Lubr. Technol., vol. 92, no. 1, Jan. 1970, pp. 39-53.

2. Horsch, J.D.: Correlation of Gyro Spin Axis Ball Bearing Performance with the Dynamic Lubricating Film. ASLE Trans, vol. 6, Apr. 1963, pp. 112-124.

3. Chiu, Y.P.: An Analysis and Prediction of Lubricant Film Starvation in Rolling Contact Systems. ASLE Trans., vol. 17, no. 1, 1974, pp. 22-35. 
4. Pamberton, J. and Cameron, A.: A Mechanism of Fluid Replenishment in Elastohydrodynamic Contacts, Wear, vol. 37, 1976, pp. 185-190.

5. Lauder, W.: Hydrodynamic Lubrication of Proximate Cylindrical Surfaces of Large Relative Curvature, Proc. Inst. Mech. Engrs., vo1. 180, pt. 3B, 1966, Pp. 101-106. (Primary source - Brewe, D.E.; and Hamrock, B.J.: Analysis of Starvation Effects on Hydrodynamic Lubrication in Nonconforming Contacts. NASA TM-82668, 1981.)

6. Tipei, N.: Boundary Conditions of a Viscous Flow Between Surfaces with Rolling and Sliding Motion. J. Lubri. Technol., vol. 90, no. 1, Jan. 1968, Pp. 254-261. (Primary source - Brewe, D.E.; and Hamrock, B.J.: Analysis of Starvation Effects on Hydrodynamic Lubrication in Nonconforming Contacts. NASA TM-82668, 1981.)

7. Saman, W.Y.: A study of Starved Elastohydrodynamic Lubrication with Particular Reference to Gyroscope Bearings. Ph.D. thesis, The University of Leeds, U.K., 1974. (Primary source - Brewe, D.E.; and Hamrock, B.J.: Analys is of Starvation Effects on Hydrodynamic Lubrication in Nonconforming Contacts. NASA TM-82668, 1981.)

8. Dowson, D.: Laboratory Experiments and Demonstrations in Tribology, Tribology, vol. 1, No. 2, Mar. 1968, pp. 104-108 and vol. 1, no. 3, Aug. 1968, pp. $150-156$.

9. Floberg, L.: On the Hydrodynamic Lubrication with Special Reference to the Subcavity Pressures and Number of Streamers in Cavitation Region, Acta. Polytech. Scand., Series ME., no. 19, 1965.

10. Floberg, L.: Lubrication of Two Rotating Cylinders of Variable Lubricant Supply with Reference to the Tensile Strength of the Liquid Lubricant. J. Lubr. Technol., vol. 95, no. 2, Apr. 1973, pp. 155-165. 
11. Wedeven, L.D.; Evans, D; and Cameron, A.: Optical Analysis of Ball Bearing Starvation. J. Lubr. Technol., vol. 93, no. 3, Ju1. 1971, pp. 349-363.

12. Oteri, B.I.: A Study of the Inlet Boundary Condition and the Effect of Surface Quality in Certain Lubrication Problems, Ph. D. thesis, University of Leeds, U.K., 1972. (Primary source - Brewe, D.E.; and Hamrock, B.J.: Analysis of Starvation Effects on Hydrodynamic Lubrication in Nonconforming Contacts. NASA TM-82668, 1981.)

13. Floberg, L.: Lubrication of a Rotating Cylinder on a Plane Surface Considering Cavitation Trans. Chalmers Univ. Technol. (Gothenberg), no. 216, 1959. (Primary source - Brewe, D.E.; and Hamrock, B.J.: Analysis of Starvation Effects on Hydrodynamic Lubrication in Nonconforming Contacts. NASA TM-82668, 1981.)

14. Floberg, L.: Lubrication of Two Cylindrical Surfaces, Considering Cavitation, Trans. Chalmers Univ. Technol., (Gothenberg) No. 234, 1961. (Primary source - Brewe, D.E.; and Hamrock, B.J.: Analysis of Starvation Effects on Hydrodynamic Lubrication in Nonconforming Contacts. NASA TM-82668, 1981.)

15. Dalmaz, G. and Godet, M.: Traction, Load and Film Thickness in Sightly Loaded Lubricated Point Contacts, J. Mech. Eng. Sci., vol. 15, no. 6, Dec. 1973, pp. 400-409.

16. Wolveridge, P.E.; Baglin, K.P; and Archard, J.F.: The Starved Lubrication of Cylinders in Line Contact Proc. Inst. Mech. Engrs. vol. 185, 81/71, 1971, pp. 1159-1169. 
17. Castie, P.; and Dowson, D.: A Theoretical Analysis of the Starved Elastohydrodynamic Lubrication Problem for Cylinders in Line Contact. Proc. Inst. Mech. Engrs. (Lond), U.K., 1972, pp. 131-137. (Primary source - Brewe, D.E.; and Hamrock, B.J.: Analysis of Starvation Effects on Hydrodynamic Lubrication in Nonconforming Contacts. NASA TM-82668, 1981.)

18. Hamrock, B.J.; and Dowson, D.: Isothermal Elastohydrodynamic Lubrication of Point Contacts, Part IV Starvation Results. J. Lubr. Technol., vol. 99, no. 1, Jan. 1977, pp. 15-23.

19. Hamrock, B.J.; and Dowson, D.: Elastohydrodynamic Lubrication of Elliptical Contacts for Materials of Low Elastic Modulus II Starved Conjunction. J. Lubr. Technol., vol. 101, no. 1, Jan. 1979, pp. 92-98.

20. Brewe, D.E.; and Hamrock, B.J.: Analysis of Starvation Effects on Hydrodynamic Lubrication in Nonconforming Contacts. J. Lubr. Technol., vol. 104, no. 3, Jul. 1982, pp. 410-417.

21. Bonneau, D.; and Frene, J.: Film Formation and Flow Characteristics at the inlet of a Starved Contact - Theoretical Study. J. Lubr. Technol., vol. 105, no. 2, Apr. 1983, pp. 178-186.

22. Sasaki, T.; Mori, H.; and Okino, N.: Fluid Lubrication Theory of Roller Bearings: Pt. I - Fluid Lubrication Theory for Two Rotating Cylinders in Contact. J. Basic Eng., vol. 84, no. 1, Mar. 1962, pp. 166-174.

23. Sasaki, T.; Mori, H.; and Okino,: Fluid Lubrication Theory of Roller Bearings: Pt. II - Flutd Lubrication Theory Applied to Roller Bearings. J. Basic Eng., vol. 84, no. 1, Mar. 1962, pp. 175-180.

24. Dowson, D.; Markho, P.H.; and Jones, D.A.: The Lubrication of Lightly Load Cylinders in Combined Rolling Sliding and Normal Motion-Pt 1 Theory. J. Lubr. Technol., vol. 98, no. 4, Oct. 1976, pp. 509-516.

25. Vichard, J.P.: Transient Effects in Lubrication of Hertzian Contacts. J. Mech. Eng. Sci, vol. 13, no. 3, 1971, p. 173. 
26. Christensen, H.: The 011 Film in a Closing Gap Proc. Roy. Soc., Series A, vol. 266, 1962, pp. 312-328.

27. Herrebrugh, K.: Elastohydrodynamic Squeeze Film between Two Cylinders in Normal Approach. J. Lubr. Technol., vol. 92, Apr. 1970, pp. 292-302.

28. Lee, K.M.; and Cheng, H.S.: The Pressure and Deformation Profiles Between Two Normally Approaching Lubricated Cylinders. J. Lubr. Technol., vol. 95, no. 3, Ju1. 1973, pp. 308-320.

29. Chandra, A.; and Rogers, R.J.: The Normal Approach Contact and Rebound of Lubricated Cylinders. J. Lubr. Technol., vol. 105, no. 2, Apr. 1983, pp. $271-279$.

30. Ghosh, M.K.; Hamrock, B.J.; and Brewe, D.E.: Hydrodynamic Lubrication of Rigid Nonconformal Contacts in Combined Rolling and Normal Motion. NASA TM-83578, 1984 . 
TABLE 1. - STEADY STATE PERFORMANCE OF STARVED NONCONFORMAL CONTACTS FOR VARIOUS GEOMETRY PARAMETERS FOR CENTRAL FILM THICKNESS $H_{0}=1.0 \times 10^{-4}$ AND NORMAL VELOCITY PARAMETER, $q=0.0$

\begin{tabular}{|c|c|c|c|c|c|c|c|c|c|c|c|c|}
\hline \multirow{2}{*}{$\begin{array}{c}\text { Inlet } \\
\text { starvation } \\
\text { parameter, } \\
H_{1 n}\end{array}$} & \multicolumn{12}{|c|}{ Geometry parameter, a } \\
\hline & W & $\begin{array}{l}P_{\max } \\
\times 10^{5}\end{array}$ & $x_{p}$ & $x_{r}$ & W & $\begin{array}{l}P_{\max } \\
\times 10^{6}\end{array}$ & $x_{p}$ & $x_{r}$ & $W$ & $\begin{array}{r}P_{\max } \\
\times 10^{6}\end{array}$ & $x_{p}$ & $x_{r}$ \\
\hline $\begin{array}{l}0.035 \\
.0175 \\
.01 \\
.005 \\
.0025 \\
.0011 \\
.0006\end{array}$ & $\begin{array}{r}171.0 \\
165.5 \\
158.4 \\
147.1 \\
130.9 \\
103.2 \\
76.2\end{array}$ & $\begin{array}{l}4.2980 \\
4.2980 \\
4.2970 \\
4.2935 \\
4.2800 \\
4.2200 \\
4.0685\end{array}$ & $\begin{array}{r}-0.008 \\
-.008 \\
-.008 \\
-.008 \\
-.008 \\
-.008 \\
-.008\end{array}$ & $\begin{array}{r}+0.003 \\
+.003 \\
+.003 \\
+.003 \\
+.003 \\
+.003 \\
+.003\end{array}$ & $\begin{array}{r}1061.2 \\
1024.5 \\
968.4 \\
911.5 \\
811.5 \\
639.3 \\
467.9\end{array}$ & $\begin{array}{l}1.2105 \\
1.2085 \\
1.2055 \\
1.2050 \\
1.1995 \\
1.1710 \\
1.1075\end{array}$ & $\begin{array}{r}-0.007 \\
-.007 \\
-.007 \\
-.007 \\
-.007 \\
-.007 \\
-.007\end{array}$ & $\begin{array}{r}+0.005 \\
+.005 \\
+.005 \\
+.005 \\
+.005 \\
+.005 \\
+.005\end{array}$ & $\begin{array}{r}10987.2 \\
10612.8 \\
10007.4 \\
9391.2 \\
8449.4 \\
6496.2 \\
4692.0\end{array}$ & $\begin{array}{l}2.082 \\
2.082 \\
2.082 \\
2.079 \\
2.068 \\
1.987 \\
1.836\end{array}$ & $\begin{array}{r}-0.007 \\
-.007 \\
-.007 \\
-.007 \\
-.007 \\
-.007 \\
-.006\end{array}$ & $\begin{array}{r}+0.007 \\
+.007 \\
+.007 \\
+.007 \\
+.007 \\
+.007 \\
+.006\end{array}$ \\
\hline
\end{tabular}

TABLE 2. - STEADY STATE PERFORMANCE OF STARVED NONCONFORMAL CONTACTS INFLUENCE OF FILM THICKNESS GEOMETRY PARAMETER, $\alpha=1.0$ AND NORMAL VELOCITY PARAMETER, $q=0.0$

\begin{tabular}{|c|c|c|c|c|c|c|c|c|}
\hline \multirow{3}{*}{$\begin{array}{c}\text { Central } \\
\text { film } \\
\text { thickness, } \\
H_{0}\end{array}$} & \multicolumn{8}{|c|}{ Inlet starvation parameter, $\mathrm{H}_{1 n}$} \\
\hline & \multicolumn{4}{|c|}{0.035} & \multicolumn{4}{|c|}{0.01} \\
\hline & W & $P_{\max }$ & $x_{p}$ & $x_{r}$ & $W$ & $P_{\max }$ & $x_{p}$ & $x_{r}$ \\
\hline \multirow[t]{2}{*}{$\begin{array}{l}1.0 \times 10^{-3} \\
5.0 \times 10^{-4} \\
1.0 \times 10^{-4} \\
1.0 \times 10^{-5}\end{array}$} & $\begin{array}{r}270.8 \\
421.9 \\
1061.2 \\
3493.8\end{array}$ & $\begin{array}{l}3.7766 \times 10^{4} \\
1.0665 \times 10^{5} \\
1.2105 \times 10^{6} \\
3.8246 \times 10^{7}\end{array}$ & $\begin{array}{l}-0.023 \\
-0.016 \\
-0.007 \\
-0.002\end{array}$ & $\begin{array}{r}+0.015 \\
+.011 \\
+.005 \\
+.002\end{array}$ & $\begin{array}{r}189.1 \\
339.2 \\
968.4 \\
3482.5\end{array}$ & $\begin{array}{l}3.6210 \times 10^{4} \\
1.0552 \times 10^{5} \\
2.082 \times 10^{6} \\
3.8167 \times 10^{7}\end{array}$ & $\begin{array}{r}-0.023 \\
-.016 \\
-.007 \\
-.002\end{array}$ & $\begin{array}{r}+0.016 \\
+.011 \\
+.005 \\
+.002\end{array}$ \\
\hline & \multicolumn{4}{|c|}{0.005} & \multicolumn{4}{|c|}{0.0025} \\
\hline $\begin{array}{l}1.0 \times 10^{-3} \\
5.0 \times 10^{-4} \\
1.0 \times 10^{-4} \\
1.0 \times 10^{-5}\end{array}$ & $\begin{array}{r}126.2 \\
267.1 \\
911.5 \\
3400.8\end{array}$ & $\begin{array}{l}3.3345 \times 10^{4} \\
1.0245 \times 10^{5} \\
1.205 \times 10^{6} \\
3.8164 \times 10^{7}\end{array}$ & $\begin{array}{r}-0.022 \\
-.016 \\
-.007 \\
-.002\end{array}$ & $\begin{array}{r}+0.015 \\
+.011 \\
+.005 \\
+.002\end{array}$ & $\begin{array}{r}54.4 \\
177.3 \\
811.5 \\
3302.2\end{array}$ & $\begin{array}{c}2.5228 \times 10^{4} \\
.9925 \times 10^{5} \\
1.995 \times 10^{6} \\
3.8158 \times 10^{7}\end{array}$ & $\begin{array}{r}-0.018 \\
-.015 \\
-.007 \\
-.002\end{array}$ & $\begin{array}{r}+0.015 \\
+.011 \\
+.005 \\
+.002\end{array}$ \\
\hline
\end{tabular}

TABLE 3. - DYNAMIC PERFORMANCE OF STARVED NONCONFORMAL CONTACTS DIMENSIONLESS CENTRAL FILM THICKNESS, $H_{0}=1.0 \times 10^{-4}$, GEOMETRY PARAMETER, $\alpha=0.2$

\begin{tabular}{|c|c|c|c|c|c|c|c|c|}
\hline \multirow{2}{*}{$\begin{array}{c}\text { Inlet } \\
\text { starvation } \\
\text { parameter, } \\
H_{\text {in }}\end{array}$} & \multicolumn{2}{|c|}{ Normal velocity parameter, $q=-1.0$} & \multicolumn{3}{|c|}{ Normal velocity parameter, $q=0.75$} \\
\cline { 2 - 9 } & & $\xi$ & $x_{p}$ & $x_{r}$ & $B$ & $\xi$ & $x_{p}$ & $x_{r}$ \\
\hline 0.035 & 2.5971 & 3.5697 & -0.003 & +0.019 & 0.4485 & 0.2232 & -0.017 & -0.007 \\
.0175 & 2.6461 & 3.5698 & -.003 & +.019 & .4323 & .2212 & -.017 & -.007 \\
.01 & 2.7096 & 3.5706 & -.003 & +.019 & .4141 & .2210 & -.017 & -.007 \\
.005 & 2.8198 & 3.5723 & -.003 & +.019 & .3823 & .2204 & -.017 & -.007 \\
.0025 & 2.9916 & 3.5786 & -.003 & +.019 & .3384 & .2182 & -.017 & -.007 \\
.0011 & 3.3443 & 3.6049 & -.003 & +.019 & .2615 & .2091 & -.017 & -.008 \\
.0006 & 3.8005 & 3.6656 & -.003 & +.019 & .1837 & .1872 & -.017 & -.008 \\
\hline
\end{tabular}


TABLE 4. - DYNAMIC PERFORMANCE OF STARVED NONCONFORMAL CONTACTS DIMENSIONLESS CENTRAL FILM THICKNESS, $H_{0}=1.0 \times 10^{-4}$, GEOMETRY PARAMETER, $\alpha=1.0$

\begin{tabular}{|c|c|c|c|c|c|c|c|c|}
\hline \multirow{2}{*}{$\begin{array}{c}\text { Inlet } \\
\text { starvation } \\
\text { parameter, } \\
\mathrm{H}_{\text {In }}\end{array}$} & \multicolumn{4}{|c|}{$\begin{array}{c}\text { Normal velocity parameter, } \\
\qquad q=-1.0\end{array}$} & \multicolumn{4}{|c|}{$\begin{array}{c}\text { Normal velocity parameter, } \\
\qquad q=0.75\end{array}$} \\
\hline & $B$ & $\xi$ & $x_{p}$ & $x_{r}$ & $B$ & $\xi$ & $x_{p}$ & $x_{r}$ \\
\hline $\begin{array}{l}0.035 \\
.0175 \\
.01 \\
.005 \\
.0025 \\
.0011 \\
.0006\end{array}$ & $\begin{array}{l}2.783 \\
2.844 \\
2.9264 \\
3.05 \\
3.246 \\
3.668 \\
4.247\end{array}$ & $\begin{array}{l}3.79 \\
3.80 \\
3.805 \\
3.8106 \\
3.8261 \\
3.8911 \\
4.0367\end{array}$ & $\begin{array}{r}-0.003 \\
-.003 \\
-.003 \\
-.003 \\
-.003 \\
-.002 \\
-.002\end{array}$ & $\begin{array}{r}+0.024 \\
+.024 \\
+.024 \\
+.024 \\
+.024 \\
+.024 \\
+.025\end{array}$ & $\begin{array}{r}0.4220 \\
.4030 \\
.3825 \\
.3490 \\
.3027 \\
.2230 \\
.1450\end{array}$ & $\begin{array}{l}0.2039 \\
.2032 \\
.2020 \\
.2011 \\
.1962 \\
.1791 \\
.1463\end{array}$ & $\begin{array}{l}-0.017 \\
-.017 \\
-.017 \\
-.017 \\
-.017 \\
-.016 \\
-.016\end{array}$ & $\begin{array}{l}-0.006 \\
-.006 \\
-.006 \\
-.006 \\
-.006 \\
-.006 \\
-.007\end{array}$ \\
\hline
\end{tabular}

TABLE 5. - DYNAMIC PERFORMANCE OF STARVED NONCONFORMAL CONTACTS DIMENSIONLESS CENTRAL FILM THICKNESS, $H_{0}=1.0 \times 10^{-4}$, GEOMETRY PARAMETER, $\alpha=35.0$

\begin{tabular}{|c|c|c|c|c|c|c|c|c|}
\hline \multirow{2}{*}{$\begin{array}{c}\text { Inlet } \\
\text { starvation } \\
\text { parameter, } \\
H_{1 n}\end{array}$} & \multicolumn{4}{|c|}{$\begin{array}{l}\text { Normal velocity parameter, } \\
\qquad q=-1.0\end{array}$} & \multicolumn{4}{|c|}{$\begin{array}{c}\text { Normal velocity parameter, } \\
q=0.75\end{array}$} \\
\hline & $B$ & $\xi$ & $x_{p}$ & $x_{r}$ & B & $\xi$ & $x_{p}$ & $x_{r}$ \\
\hline $\begin{array}{l}0.035 \\
.0175 \\
.01 \\
.005 \\
.0025 \\
.0011 \\
.0006\end{array}$ & $\begin{array}{l}2.9931 \\
3.0666 \\
3.1671 \\
3.3032 \\
3.5181 \\
4.0607 \\
4.8118\end{array}$ & $\begin{array}{l}4.1668 \\
4.1670 \\
4.1685 \\
4.1731 \\
4.1907 \\
4.3141 \\
4.5562\end{array}$ & $\begin{array}{r}-0.002 \\
-.002 \\
-.002 \\
-.002 \\
-.002 \\
-.002 \\
-.002\end{array}$ & $\begin{array}{r}+0.029 \\
+.030 \\
+.030 \\
+.030 \\
+.030 \\
+.030 \\
+.030\end{array}$ & $\begin{array}{r}0.3966 \\
.3755 \\
.3546 \\
.3193 \\
.2737 \\
.1923 \\
.1189\end{array}$ & $\begin{array}{l}0.1821 \\
.1821 \\
.1800 \\
.1794 \\
.1749 \\
.1531 \\
.1194\end{array}$ & $\begin{array}{r}-0.016 \\
-.016 \\
-.016 \\
-.016 \\
-.016 \\
-.016 \\
-.015\end{array}$ & $\begin{array}{l}-0.005 \\
-.005 \\
-.005 \\
-.005 \\
-.005 \\
-.005 \\
-.006\end{array}$ \\
\hline
\end{tabular}

TABLE 6. - DYNAMIC PERFORMANCE OF STARVED NONCONFORMAL CONTACTS INFLUENCE OF CENTRAL FILM THICKNESS: GEOMETRY PARAMETER, $\alpha=1.0$, INLET STARVATION PARAMETER, $H_{7 n}=0.035$ and 0.01

\begin{tabular}{|c|c|c|c|c|c|c|c|c|c|}
\hline \multirow{2}{*}{$\begin{array}{c}\text { Central } \\
\text { film } \\
\text { thickness, } \\
\mathrm{H}_{\mathrm{o}} \\
\end{array}$} & \multirow[t]{2}{*}{$H_{1 n}$} & \multicolumn{4}{|c|}{$\begin{array}{c}\text { Normal velocity parameter, } \\
q=-1.0\end{array}$} & \multicolumn{4}{|c|}{$\begin{array}{c}\text { Normal velocity parameter, } \\
\qquad \begin{array}{c}q=0.75\end{array}\end{array}$} \\
\hline & & $B$ & $\xi$ & $x_{p}$ & $x_{r}$ & $B$ & $\xi$ & $x_{p}$ & $x_{r}$ \\
\hline $\begin{array}{l}1.0 \times 10^{-3} \\
5.0 \times 10^{-4} \\
1.0 \times 10^{-4} \\
1.0 \times 10^{-5}\end{array}$ & 0.035 & $\begin{array}{l}2.98 \\
2.8123 \\
2.783 \\
2.62\end{array}$ & $\begin{array}{l}3.7408 \\
3.7717 \\
3.7900 \\
3.7588\end{array}$ & $\begin{array}{r}-0.008 \\
-.006 \\
-.003 \\
-.001\end{array}$ & $\begin{array}{r}+0.043 \\
+.031 \\
+.024 \\
+.007\end{array}$ & $\begin{array}{c}0.332 \\
.3700 \\
.422 \\
.454\end{array}$ & $\begin{array}{r}0.2017 \\
.2025 \\
.2039 \\
.2074\end{array}$ & $\begin{array}{r}-0.054 \\
-.037 \\
-.017 \\
-.005\end{array}$ & $\begin{array}{r}-0.020 \\
-.013 \\
-.006 \\
-.002\end{array}$ \\
\hline $\begin{array}{l}1.0 \times 10^{-3} \\
5.0 \times 10^{-4} \\
1.0 \times 10^{-4} \\
1.0 \times 10^{-5}\end{array}$ & 0.01 & $\begin{array}{l}3.5489 \\
3.2786 \\
2.9264 \\
2.6310\end{array}$ & $\begin{array}{l}3.8737 \\
3.8378 \\
3.8050 \\
3.7577\end{array}$ & $\begin{array}{r}0-.008 \\
-.006 \\
-.003 \\
-.001\end{array}$ & $\begin{array}{r}0+.043 \\
+.039 \\
+.024 \\
+.007\end{array}$ & $\begin{array}{r}0.2115 \\
.2833 \\
.3824 \\
.4492\end{array}$ & $\begin{array}{r}0.1761 \\
.1930 \\
.2020 \\
.2077\end{array}$ & $\begin{array}{r}-0.051 \\
-.037 \\
-.017 \\
-.005\end{array}$ & $\begin{array}{r}-0.016 \\
-.014 \\
-.006 \\
-.002\end{array}$ \\
\hline
\end{tabular}



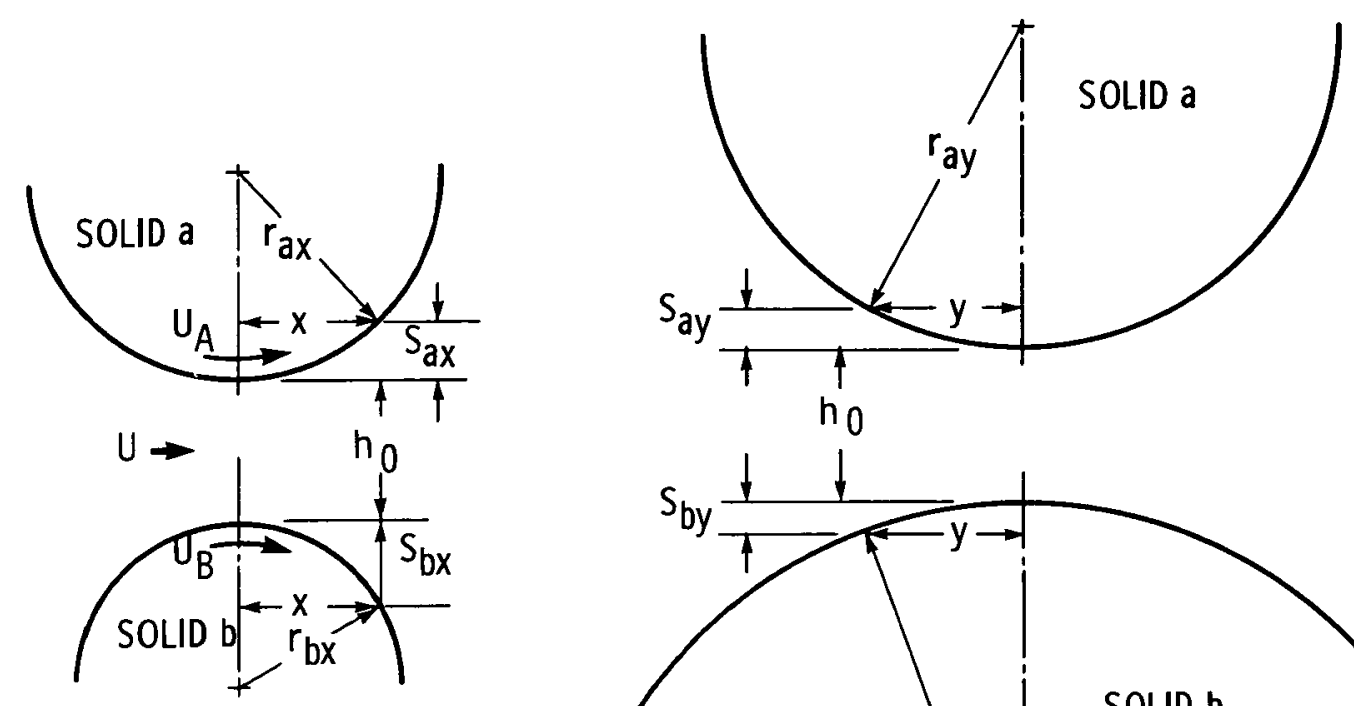

(a-1) y - 0 plane

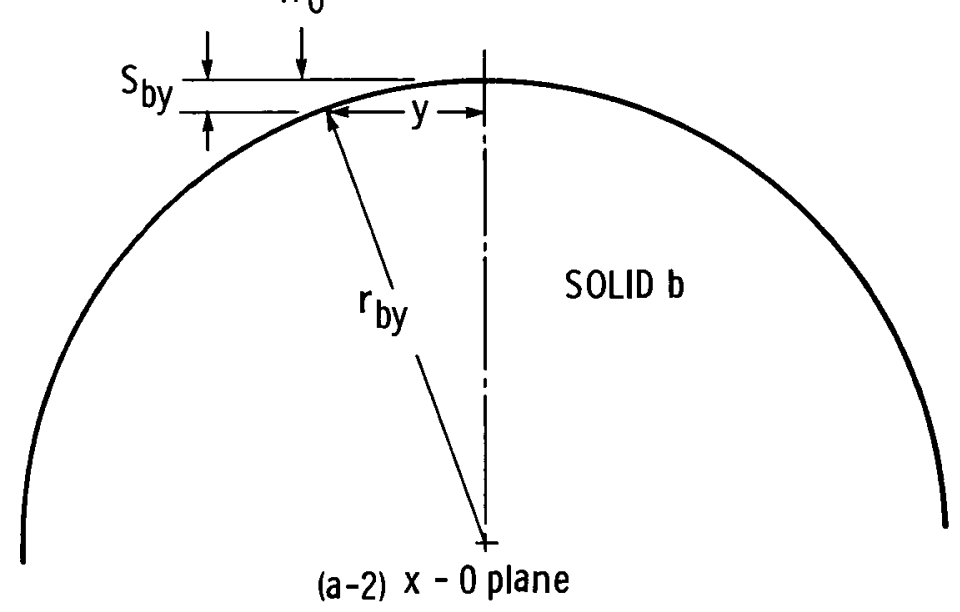

(a) Two rigid solids separated by a lubricant film.
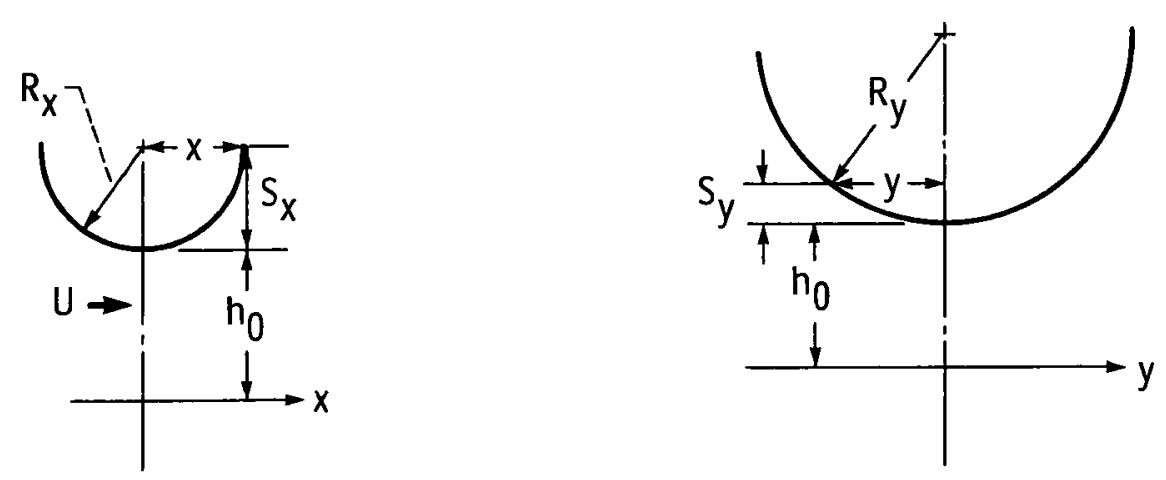

$y-0$ plane

$x-0$ plane

(b) Equivalent system of a rigid solid near a plane separated by a lubricant film.

Figure 1. - Contact geometry. 
TABLE 7. - DYNAMIC PERFORMANCE OF STARVED NONCONFORMAL CONTACTS INFLUENCE OF CENTRAL FILM THICKNESS FOR GEOMETRY PARAMETER, $\alpha=1.0$, INLET STARVATION

PARAMETER $H_{1 n}=0.005$

\begin{tabular}{|c|c|c|c|c|c|c|c|c|}
\hline \multirow{2}{*}{$\begin{array}{c}\text { Central } \\
\text { film } \\
\text { thickness, } \\
H_{0}\end{array}$} & \multicolumn{4}{|c|}{$\begin{array}{l}\text { Normal velocity parameter, } \\
\qquad q=-1.0\end{array}$} & \multicolumn{4}{|c|}{$\begin{array}{l}\text { Normal velocity parameter, } \\
\qquad \mathrm{q}=0.75\end{array}$} \\
\hline & B & $\xi$ & $x_{p}$ & $x_{r}$ & B & $\xi$ & $x_{p}$ & $x_{r}$ \\
\hline $\begin{array}{l}1.0 \times 10^{-3} \\
5.0 \times 10^{-4} \\
1.0 \times 10^{-4} \\
1.0 \times 10^{-5}\end{array}$ & $\begin{array}{l}4.3075 \\
3.6990 \\
3.0500 \\
2.6678\end{array}$ & $\begin{array}{l}4.0887 \\
3.9152 \\
3.8106 \\
3.7580\end{array}$ & $\begin{array}{r}-0.008 \\
-.006 \\
-.003 \\
-.001\end{array}$ & $\begin{array}{r}+0.045 \\
+.040 \\
+.024 \\
+.007\end{array}$ & $\begin{array}{l}0.1197 \\
.2123 \\
.3490 \\
.4377\end{array}$ & $\begin{array}{r}0.1343 \\
.1753 \\
.2011 \\
.2076\end{array}$ & $\begin{array}{r}-0.049 \\
-.036 \\
-.017 \\
-.005\end{array}$ & $\begin{array}{r}-0.021 \\
-.014 \\
-.006 \\
-.002\end{array}$ \\
\hline
\end{tabular}

TABLE 8. - DYNAMIC PERFORMANCE OF STARVED NONCONFORMAL CONTACTS INFLUENCE OF CENTRAL FILM THICKNESS FOR GEOMETRY PARAMETER, $\alpha=1.0$, INLET STARVATION

$$
\text { PARAMETER } H_{1 n}=0.0025
$$

\begin{tabular}{|c|c|c|c|c|c|c|c|c|}
\hline $\begin{array}{c}\text { Central } \\
\text { f llm } \\
\text { thickness, } \\
H_{0}\end{array}$ & \multicolumn{3}{|c|}{$\begin{array}{c}\text { Normal velocity parameter, } \\
q=-1.0\end{array}$} & \multicolumn{4}{c|}{$\begin{array}{c}\text { Normal velocity parameter, } \\
q=0.75\end{array}$} \\
\cline { 2 - 9 } & $B$ & $\xi$ & $x_{p}$ & $x_{r}$ & $B$ & $\xi$ & $x_{p}$ & \multicolumn{1}{c|}{$x_{r}$} \\
\hline $1.0 \times 10^{-3}$ & 6.1710 & 4.8156 & -0.005 & +0.045 & 0.021 & 0.0407 & -0.041 & -0.025 \\
$5.0 \times 10^{-4}$ & 4.5341 & 4.1410 & -.005 & +.045 & .1168 & .1296 & -.034 & -.015 \\
$1.0 \times 10^{-4}$ & 3.246 & 3.8261 & -.002 & +.030 & .3027 & .1962 & -.016 & -.005 \\
$1.0 \times 10^{-5}$ & 2.7140 & 3.7584 & -.001 & +.001 & .4236 & .2075 & -.005 & -.002 \\
\hline
\end{tabular}



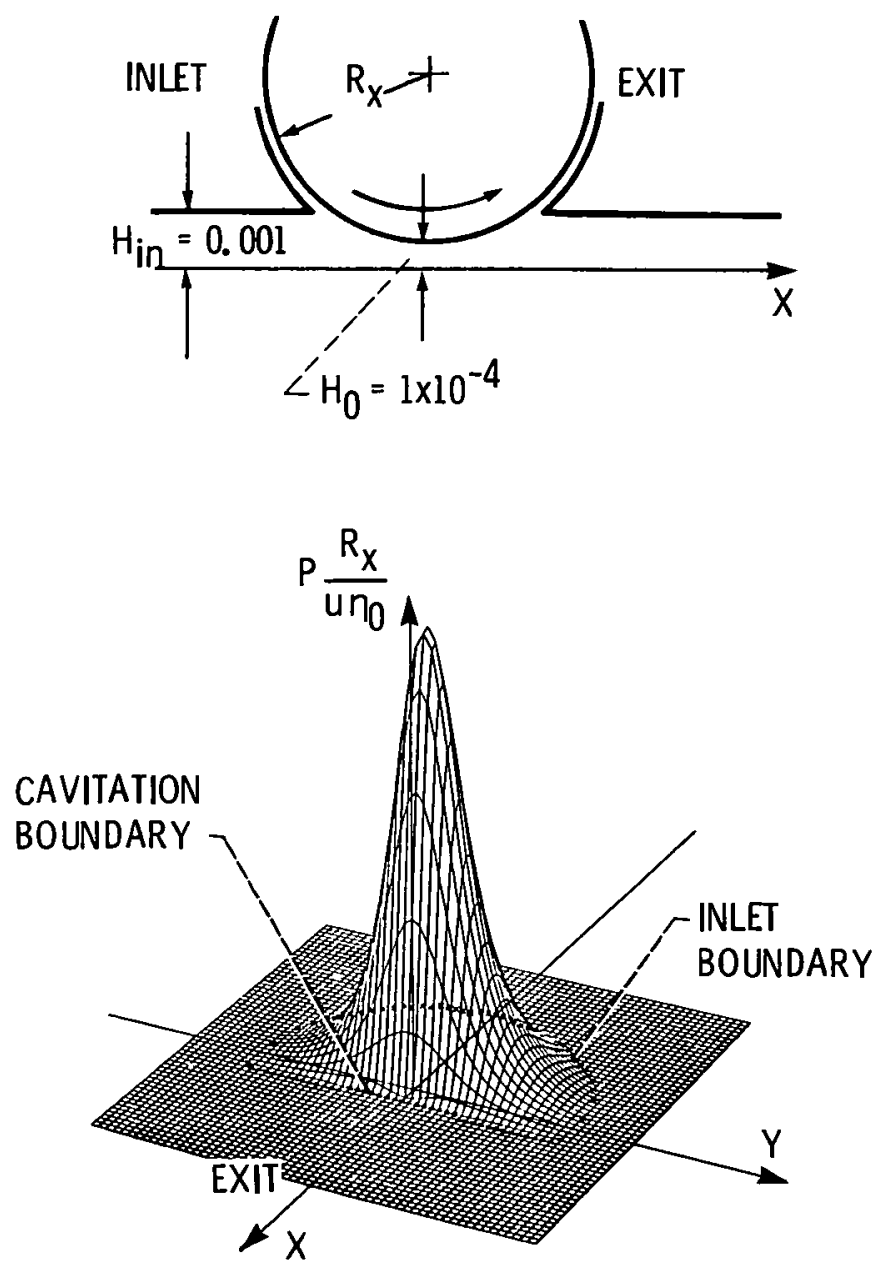

Figure 2. - Three dimensional representation of pressure distribution in starved contact, dimensionless fluid inlet level, $H_{\text {in }}=0.001$, geometry parameter, $\alpha=1.0$. 

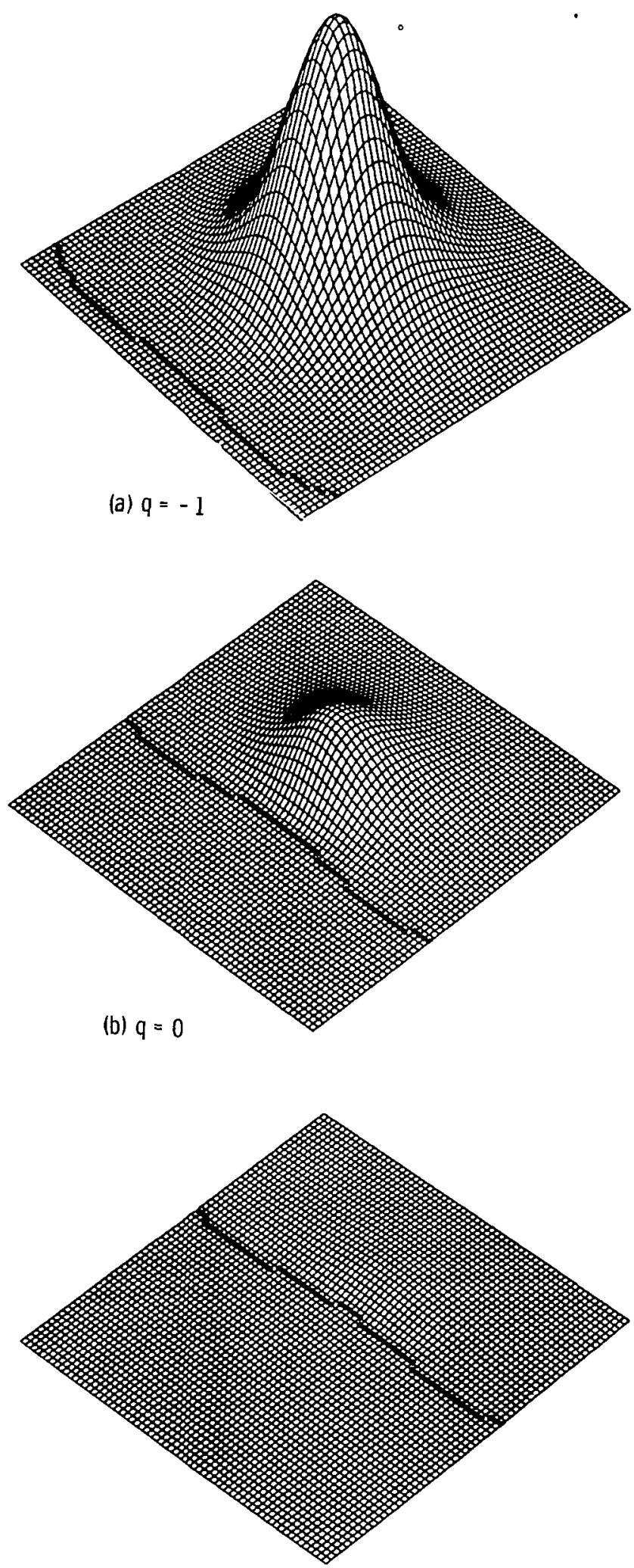

(c) $q=0.75$

Figure 3. - Pressure distribution in the contact for various dimensionless normal velocity parameters, $q$, for the dimiensionless central film thickness, $H_{0}=1.0 \times 10^{-4}$, dimensionless geometry parameter, $\alpha=1.0$, dimensionless inlet starvation parameter, $H_{1 n}=0.0006$. 


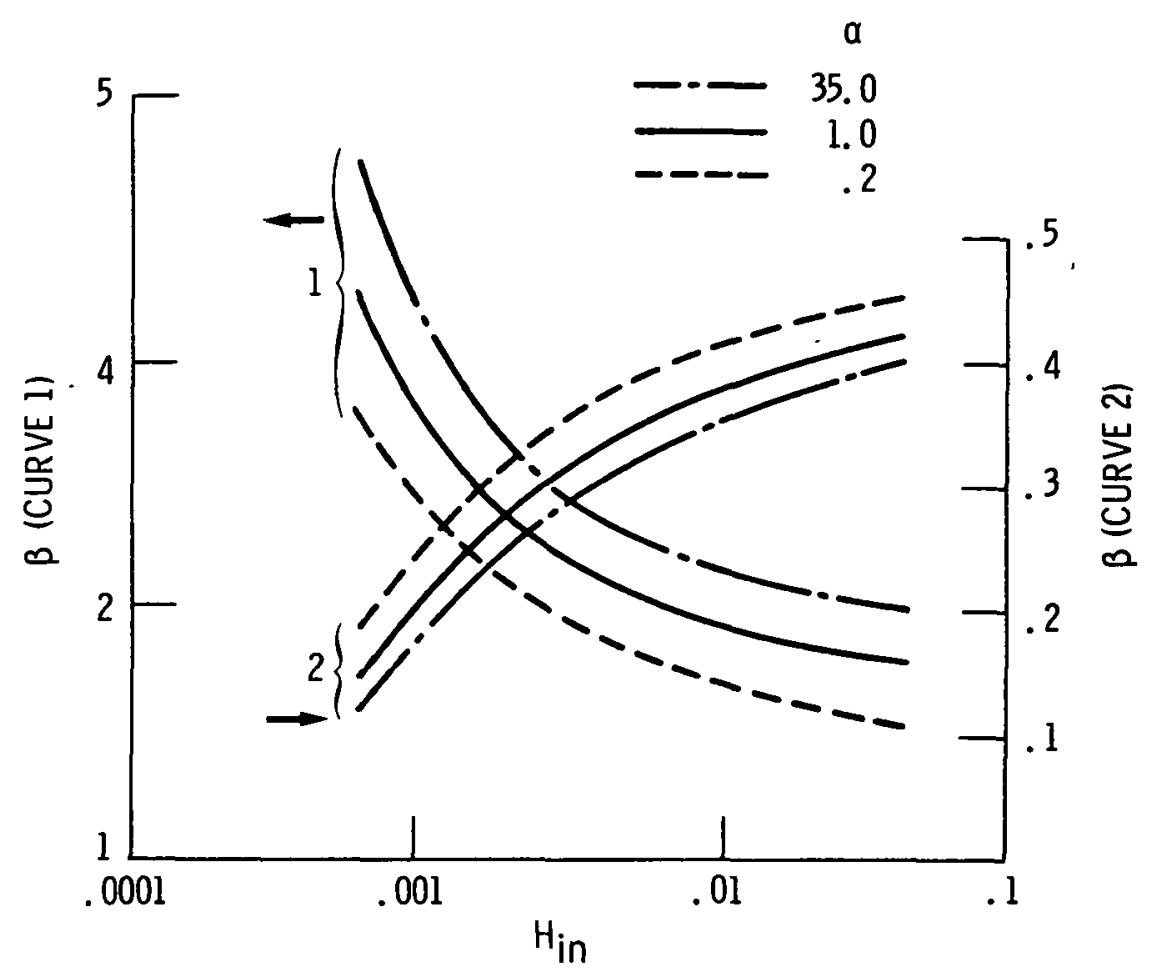

Figure 4. - Variation of dynamic load ratio, $\beta$, with the dimensionless inlet starvation parameter, $H_{\text {in }}$, for varjous geometry parameters, for the dimensionless central film thickness, $H_{0}=1.0 \times 10^{-4}$.

Curve 1 for normal approach, $q=-1.0$.

Curve 2 for normal separation, $q=0.75$. 


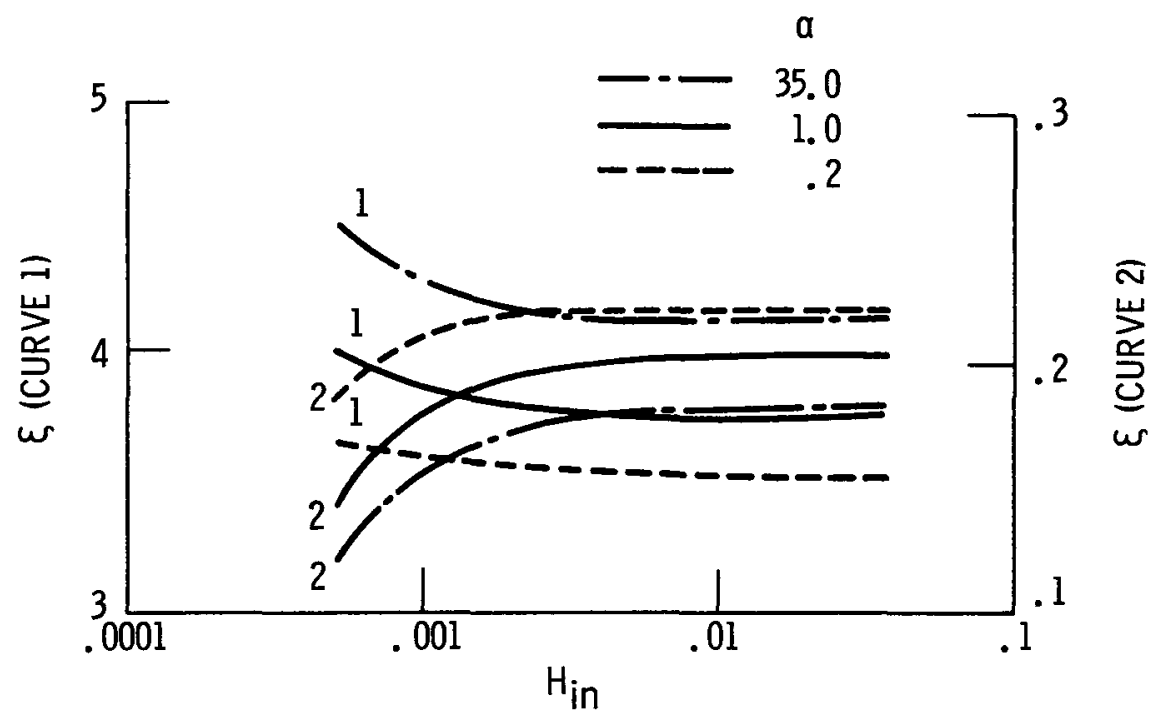

Figure 5. - Variation of dynamic peak pressure ratio, $\xi$, with the dimensionless inlet starvation parameter, $\mathrm{H}_{\mathrm{in}}$. for various geometry parameters, for central film thickness, $H_{0}=1.0 \times 10^{-4}$.

Curve 1 for normal approach, $q=-1.0$.

Curve 2 for normal separation, $q=0.75$. 


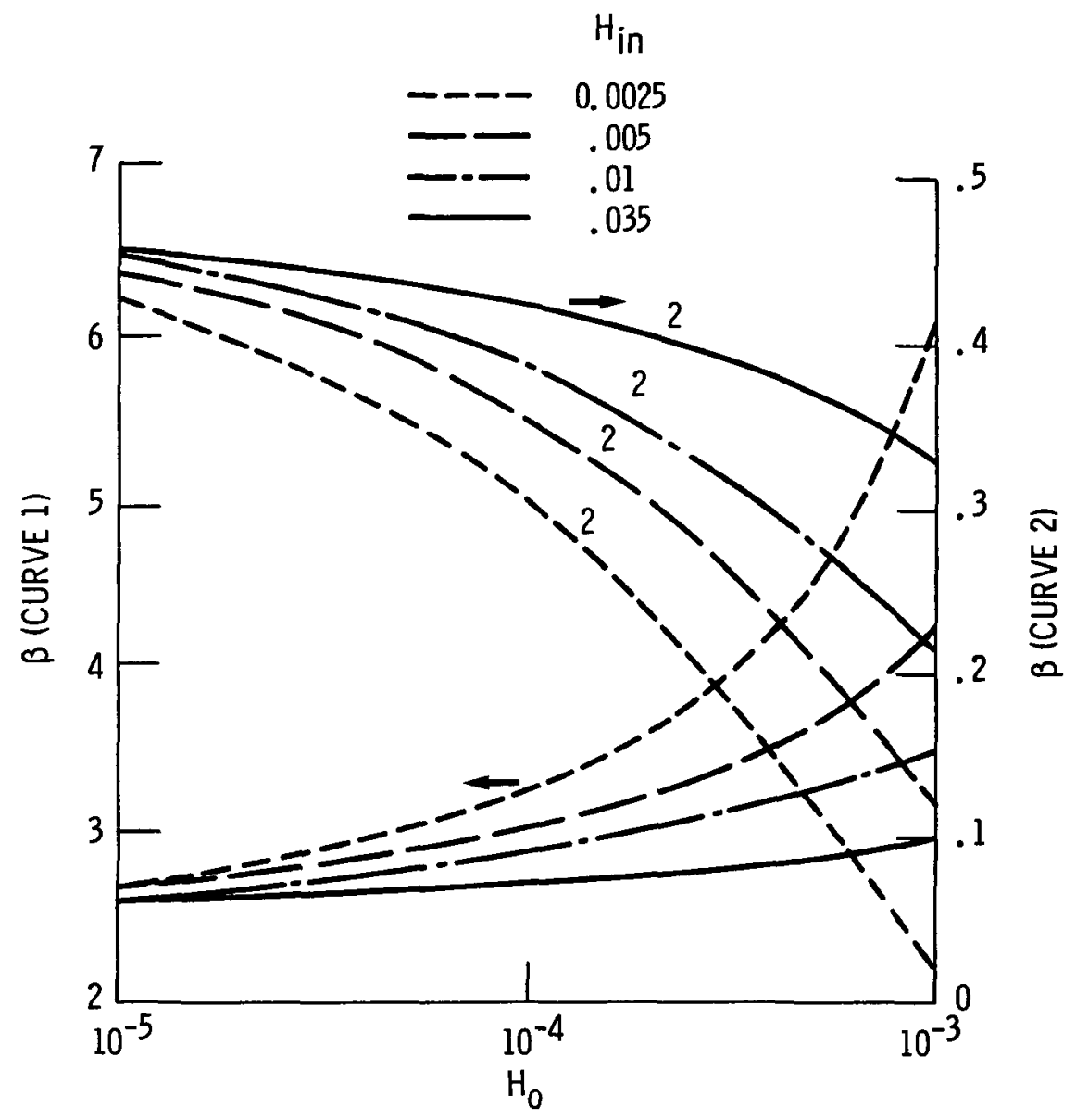

Figure 6. - Variation of dynamic load ratio, $\beta$, with central film thickness, $H_{0}$, for various inlet starvation parameters, for geometry parameter, $\alpha=1.0$.

Curve 1 for normal approach, $q=-1.0$.

Curve 2 for normal separation, $q=0.75$. 


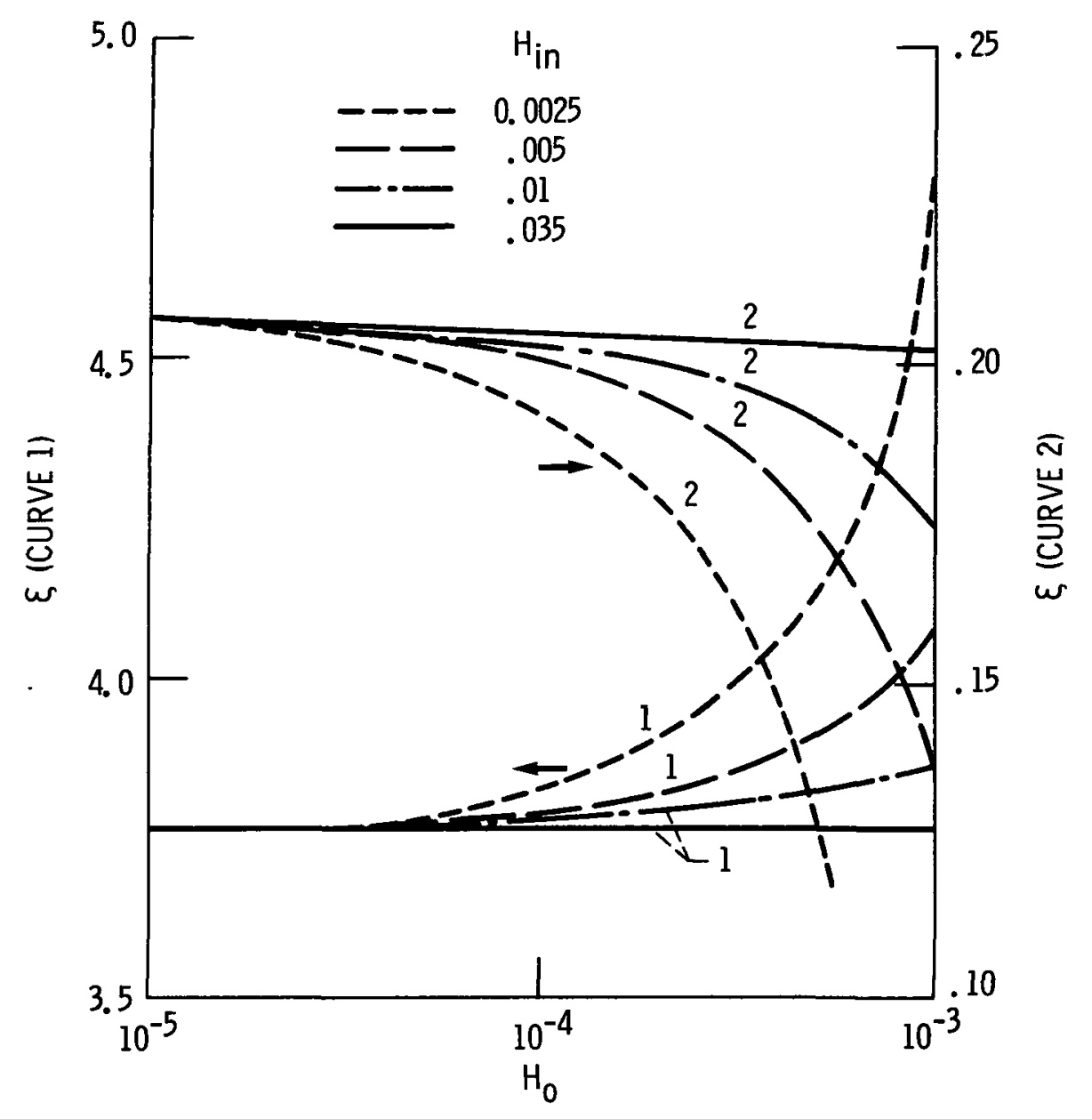

Figure 7. - Variation of dynamic peak pressure ratio, $\xi$, with central film thickness, $H_{0}$, for various inlet starvation parameters, for geometry parameter, $\alpha=1.0$. Curve 1 for normal approach, $q=-1.0$.

Curve 2 for normal separation, $q=0.75$. 


\begin{tabular}{|c|c|c|c|}
\hline $\begin{array}{c}1 \text { Report No NASA TM- } 87174 \\
\text { USAAVSCOM-TR-85-C }-20\end{array}$ & \multicolumn{2}{|c|}{2 Government Accession No } & 3 Reciplent's Catalog No \\
\hline \multirow{2}{*}{\multicolumn{3}{|c|}{$\begin{array}{l}4 \text { Title and Subitle } \\
\text { Starvation Effects on the Hydrodynamic Lubrication } \\
\text { of Rigid Nonconformal Contacts in Combined } \\
\text { Rolling and Normal Motion }\end{array}$}} & 5. Report Date \\
\hline & & & $\begin{array}{l}6 \text { Performing Organization Code } \\
505-63-81\end{array}$ \\
\hline \multirow{3}{*}{\multicolumn{3}{|c|}{7 Author(s) }} & 8 Performing Organization Report No \\
\hline & & & $E-2817$ \\
\hline & & & 10 Work Unit No. \\
\hline \multirow{2}{*}{\multicolumn{3}{|c|}{$\begin{array}{l}9 \text { Performing Organization Name and Address } \\
\text { NASA Lewis Research Center and Propulsion Directorate, } \\
\text { U.S. Army Aviation Research and Technology Activity - } \\
\text { AVSCOM, Cleveland, Ohio } 44735\end{array}$}} & \\
\hline & & & 13. Tyoe of Reoort and Period Covered \\
\hline \multicolumn{3}{|l|}{12 Sponsoring Agency Name and Address } & Technical Memorandum \\
\hline \multicolumn{3}{|c|}{$\begin{array}{l}\text { National Aeronautics and Space Administration } \\
\text { Washington, D.C. } 20546 \text { and U.S. Army Aviation } \\
\text { Systems Command, St. Louis, Mo. } 63120\end{array}$} & 14 Sponsoring Agency Code \\
\hline \multicolumn{4}{|c|}{$\begin{array}{l}15 \text { Supplementary Notes } \\
\text { M.K. Ghosh, Banaras Hindu University, Varanasi, India and NRC-NASA Research Associate; B.J. Hamrock, } \\
\text { Ohio State University, Columbus, Ohio; D.E. Brewe, Propulsion Directorate, U.S. Army Aviation Research } \\
\text { and Technology Activity - AVScom, Lewis Research Center, Cleveland, Ohio, Prepared for the } 1986 \\
\text { Annual Meeting of the American Society of Lubrication Engineers, Toronto, Canada, May 12-15, } 1986 .\end{array}$} \\
\hline \multicolumn{4}{|c|}{$\begin{array}{l}16 \text { Abstract } \\
\text { The effect of inlet starvation on the hydrodynamic lubrication of lightly loaded } \\
\text { rigid nonconformal contacts in combined rolling and normal motion is determined } \\
\text { through a numerical solution of the Reynolds' equation for an isoviscous, incom- } \\
\text { pressible lubricant. Starvation is effected by systematically reducing the fluid } \\
\text { inlet level. The pressures are taken to be ambient at the inlet meniscus boun- } \\
\text { dary and Reynolds boundary condition is applied for film rupture in the exit } \\
\text { region. Results are presented for the dynamic performance of the starved con- } \\
\text { tacts in combined rolling and normal motion for both normal approach and sepa- } \\
\text { ration. It has been found that during normal approach the dynamic load ratio } \\
\text { (i.e. ratio of dynamic to steady state load capacity) increases considerably } \\
\text { with increase in the inlet starvation. The reverse effect is observed during } \\
\text { separation when the dynamic load ratio reduces significantly. The effect of } \\
\text { starvation on the dynamic peak pressure ratio is relatively smali. Further, it } \\
\text { has been observed that with increasing starvation, film thickness effects become } \\
\text { significant in the dynamic behavior of the nonconformal contacts. For signifi- } \\
\text { cantly starved contacts the dynamic load ratio increases with increase in film } \\
\text { thickness during normal approach and a similar reduction is observed during } \\
\text { separation. A similar effect is noted for the dynamic peak pressure ratio. } \\
\text { Ninety five cases were run to incorporate the effects of starvation and film } \\
\text { thickness on the dynamic load ratio and the peak pressure ratio as obtained in } \\
\text { an earlier investigation for fully flooded contacts. }\end{array}$} \\
\hline \multicolumn{4}{|l|}{17 Key Words (Suggested by Author(s)) } \\
\hline \multicolumn{2}{|c|}{$\begin{array}{l}\text { Starvation; Hydrodynamic; Normal motion; } \\
\text { Squeeze effects; Lubrication }\end{array}$} & \multicolumn{2}{|c|}{$\begin{array}{l}\text { Unclassified - unlimited } \\
\text { STAR Category } 34\end{array}$} \\
\hline $\begin{array}{l}19 \text { Security Classif (of this report) } \\
\text { Unclass if fed }\end{array}$ & $\begin{array}{r}\text { Security Classif of this } \\
\text { Unc las }\end{array}$ & ified & 21 No of pages \\
\hline
\end{tabular}

"For sale by the Natıonal Technıcal Information Service, Sprıngfıeld, Vırgınıa 22161 
Postage and Fees Paid National Aeronautics and Space Administration NASA-451 